\title{
Tissue factor pathway inhibitor gene transfer prevents vascular smooth muscle cell proliferation by interfering with the MCP-3/CCR2 pathway
}

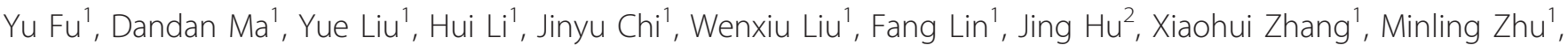 \\ Yong Zhao ${ }^{3}$ and Xinhua Yin ${ }^{1}$
}

Increased vascular smooth muscle cell (VSMC) proliferation substantially contributes to the pathogenesis of atherosclerosis and intimal hyperplasia after vascular injury. The importance of inflammation in VSMC proliferation is now being recognized. Preventing the inflammatory response is one therapeutic strategy that can be used to inhibit atherosclerosis in the clinic. The present study, using RNA interference and gene transfer techniques, was conducted to investigate the effect of monocyte chemotactic protein-3 (MCP-3) on VSMC proliferation that is a result of TNF- $a$ stimulation, and whether overexpression of the tissue factor pathway inhibitor (TFPI) gene could prevent VSMC proliferation by blocking the MCP-3/CC chemokine receptor 2 (CCR2) pathway. Mouse VSMCs were infected in vitro with recombinant adenoviruses containing either mouse MCP-3-shRNA (Ad-MCP-3-shRNA), the TFPI gene (Ad-TFPI), or the negative control, which was shRNA encoding the sequence for EGFP (Ad-EGFP) or DMEM only. The cells were then stimulated with TNF- $\alpha$ for different time periods on the third day after gene transfer. The data show that VSMC proliferation in the Ad-MCP-3-shRNA and AdTFPI groups was markedly decreased using BrdU ELISA and MTT assays; MCP-3-shRNA and TFPI inhibited the expression of MCP-3 and CCR2 after long-term stimulation and inhibited the phosphorylation of ERK1/2 and AKT after short-term stimulation, as shown by ELISA and western blot analysis. This study provides convincing evidence that clarifies the effect of the proinflammatory factor MCP-3 in promoting VSMC proliferation. Our data also show, for the first time, that TFPI has an anti-proliferative role in TNF- $\alpha$ stimulated-VSMCs at least partly by interfering with the MCP-3/CCR2 pathway and then via suppression of the ERK1/2 and PI3K/AKT signaling pathways. We conclude that TFPI gene transfer may be a safe and effective therapeutic tool for treating atherosclerosis and intimal hyperplasia.

Laboratory Investigation (2015) 95, 1246-1257; doi:10.1038/labinvest.2015.106; published online 24 August 2015

Increased vascular smooth muscle cell (VSMC) proliferation substantially contributes to the pathogenesis of atherosclerosis and intimal hyperplasia after vascular injury. ${ }^{1-3}$ A preponderance of evidence from clinical and experimental studies supports the notion that inflammation has important roles in a wide range of cardiovascular diseases, such as atherosclerosis and intimal hyperplasia, as well as cell proliferation. ${ }^{4,5}$ Current evidence has demonstrated that chemokines, which belong to proinflammatory factors, have a pivotal role in VSMC proliferation. Inhibition of chemokine activity is a possible therapeutic strategy for vascular proliferative disorders. ${ }^{6}$ Monocyte chemotactic protein-3 (MCP-3), also known as
CCL7, belongs to the MCP subfamily of the CC chemokines, which also includes MCP-1/CCL2. ${ }^{7}$ MCP-1 is present in atherosclerotic lesions and it is crucial for the development of atherosclerotic plaques. ${ }^{8}$ However, compared with MCP-1, little is known about the role of MCP-3 in vascular pathologies such as atherosclerosis and restenosis. A recent study revealed that MCP-3-deficient mice showed markedly reduced monocyte recruitment to inflammatory sites. ${ }^{9}$ Maddaluno et al ${ }^{10}$ demonstrated that MCP-3 is produced by human coronary artery smooth muscle cells (CASMCs) and directly induces CASMC proliferation in vitro, suggesting a potential role for this chemokine in vascular pathology.

\footnotetext{
${ }^{1}$ Department of Cardiology, The First Affiliated Hospital of Harbin Medical University, Harbin, Heilongjiang, China; ${ }^{2}$ Department of Oncology, The Third Affiliated Hospital of Harbin Medical University, Harbin, Heilongjiang, China and ${ }^{3}$ Department of General Surgery, The First Affiliated Hospital of Harbin Medical University, Harbin, Heilongjiang, China

Correspondence: Dr Y Zhao, MD, Department of General Surgery, The First Affiliated Hospital of Harbin Medical University, No. 23, YouZheng Road, NanGang District, Harbin 150001, Heilongjiang Province, China or Professor X Yin, MD, PhD, Department of Cardiology, The First Affiliated Hospital of Harbin Medical University, No. 23, YouZheng Road, NanGang District, Harbin 150001, Heilongjiang Province, China.
}

E-mail: zhaoyonghyd@163.com or yinxinhua0910@aliyun.com

Received 19 January 2015; revised 12 June 2015; accepted 16 June 2015 
Tissue factor pathway inhibitor (TFPI) is an anticoagulant protein found in serum that has a critical role in regulating tissue factor (TF)-mediated blood coagulation. ${ }^{11}$ TFPI is a Kunitz-type protease inhibitor consisting of three Kunitz-type domains. It regulates $\mathrm{TF}$ activity through the formation of TFPI/FXa/FVIIa/TF, and thus exerts anticoagulant and antithrombotic effects. Previous studies from our group and others have demonstrated that TFPI gene transfer or recombinant TFPI (rTFPI) irrigation can significantly reduce restenosis by inhibiting thrombosis and preventing neointimal hyperplasia. ${ }^{12-14}$ Our in vitro experiments have indicated that TFPI can induce VSMC apoptosis and thereby reduce the formation of neointima. ${ }^{15,16}$ However, little is known about the effect of TFPI on VSMC proliferation at the present time; therefore, the mechanisms underlying the efficacy of TFPI in controlling neointimal formation and atherosclerosis require further elucidation.

Because MCP-3 may be a major contributor to VSMC proliferation and atherosclerosis, ${ }^{10}$ we determined in a previous study that TFPI can inhibit the mRNA expression of MCP-3 induced by TNF- $\alpha$ in cultured rat VSMCs, ${ }^{17}$ but the mechanism remains unclear. Here, we clarified the function of MCP-3 in the proliferation of VSMCs by constructing an adenovirus-containing mouse MCP-3-shRNA (Ad-MCP-3shRNA) and infecting mouse VSMCs with it. In addition, we examined the role of TFPI in regulating the proliferation of VSMCs cultured in vitro in response to TNF- $\alpha$ and further elucidated the anti-proliferative mechanism of TFPI, with emphasis on the expression of MCP-3 and its receptor CC chemokine receptor 2 (CCR2) and on the phosphorylation of the ERK1/2 and PI3K/AKT signaling pathways.

\section{MATERIALS AND METHODS \\ Adenovirus Construction}

The adenovirus containing the human TFPI gene (Ad-TFPI) $\left(5 \times 10^{8} \mathrm{pfu} / \mathrm{ml}\right)$ was obtained from Dr Yin Xinhua (The First Affiliated Hospital of Harbin Medical University, Harbin, China). Both the adenovirus containing mouse MCP-3shRNA (Ad-MCP-3-shRNA) $\left(1 \times 10^{9} \mathrm{pfu} / \mathrm{ml}\right)$ and the adenovirus containing the negative control shRNA $\left(1 \times 10^{9}\right.$ $\mathrm{pfu} / \mathrm{ml}$ ), which encoded the sequences for enhanced green fluorescent protein (EGFP), were constructed by Wuhan GeneSil Biotechnology (Wuhan, China).

\section{Cell Culture}

Mouse VSMCs were cultured using the explantation technique from the aortic segments of 8- to 12-week-old C57BL/6 mice, and cells between passages three and six were used in the experiments. VSMCs were maintained at $37^{\circ} \mathrm{C}, 5 \% \mathrm{CO}_{2}$ in Dulbecco's Modified Eagles Medium (DMEM) containing $10 \%$ fetal bovine serum (FBS) (Hyclone, UT, USA).

\section{Adenovirus Infection}

The VSMCs were grown in 6-well plates in DMEM containing $10 \%$ FBS. When the cells were nearly $70-80 \%$ confluent, the cells were serum deprived for $24 \mathrm{~h}$. Ad-MCP-3-shRNA, Ad-TFPI, or Ad-EGFP was then added to the medium, respectively, at a multiplicity of infection (MOI) of 100. Two hours later, the cells were washed three times with phosphatebuffered saline (PBS), and then the medium was changed to DMEM containing 10\% FBS. As a control in all experiments, an identical group of cells was left uninfected and was incubated for $2 \mathrm{~h}$ in serum-free DMEM.

\section{Stimulating Vascular Smooth Muscle Cells Using TNF- $a$ on the Third Day After Gene Transfer}

On the third day after gene transfer, VSMCs were stimulated with recombinant mouse TNF- $\alpha \quad(10 \mathrm{ng} / \mathrm{ml}$, Peprotech Technologies, NJ, USA) for different time periods and were then prepared for detection. VSMCs those were not stimulated with TNF- $\alpha$ were considered as the control group.

\section{Enzyme-Linked Immunosorbent Assay}

Cell culture mediums from each group were collected on the first, third, fifth, and seventh days after gene transfer, and quantitative determination of TFPI expression was performed using a specific enzyme-linked immunosorbent assay (ELISA) kit for human TFPI protein (American Diagnostica, CT, USA) following the manufacturer's instructions.

In the other VSMCs, cells were seeded in 24-well plates at a density of $5 \times 10^{4}$ cells/well. Three days after gene transfer, the cells were stimulated with recombinant mouse TNF- $\alpha(10 \mathrm{ng} /$ $\mathrm{ml}$ ) for $6,12,24$, or $48 \mathrm{~h}$, after which the media were collected and centrifuged at $12000 \mathrm{~g}$ for $15 \mathrm{~min}$ at $4{ }^{\circ} \mathrm{C}$; the extracted supernatants were immediately frozen at $-80^{\circ} \mathrm{C}$ until use. The MCP-3 levels in the cell supernatants were evaluated using a mouse MCP-3 ELISA kit according to the manufacturer's instructions (R\&D Systems, MN, USA).

\section{Cell Proliferation Studies}

VSMC proliferation was analyzed via measuring DNA synthesis with a colorimetric bromodeoxyuridine (BrdU) ELISA kit according to the manufacturer's instructions (Shanghai JinMa Laboratory and Equipment Company, Shanghai, China). Briefly, VSMCs were seeded in 24-well plates at a density of $5 \times 10^{4}$ cells/well. Three days after gene transfer, the cells were stimulated with recombinant mouse TNF- $\alpha(10 \mathrm{ng} / \mathrm{ml})$ for 24 or $48 \mathrm{~h}$, after which the cell culture supernatants were collected and centrifuged at $12000 \mathrm{~g}$ for $15 \mathrm{~min}$ at $4{ }^{\circ} \mathrm{C}$; the extracted supernatants were immediately frozen at $-80^{\circ} \mathrm{C}$ until use. Absorbance values at $450 \mathrm{~nm}$ were determined using an ELISA reader (Bio-Rad, CA, USA).

In a separate set of experiments, VSMC proliferation was evaluated using the methyl thiazolyl tetrazolium (MTT) assay. Briefly, VSMCs were plated in 96 multi-well plates at a density of $5 \times 10^{3}$ cells/well. Three days after gene transfer, the cells were stimulated with recombinant mouse TNF- $\alpha(10 \mathrm{ng} / \mathrm{ml})$ for 24 or $48 \mathrm{~h}$, and then $0.5 \mathrm{mg} / \mathrm{ml}$ of MTT in PBS was added to each well. After $4 \mathrm{~h}$, the cell culture supernatants were removed and $150 \mu \mathrm{l}$ of DMSO was added to each well to 
dissolve the crystals. The absorbance values at $490 \mathrm{~nm}$ were obtained using an ELISA reader (Bio-Rad).

\section{Total Cellular Extracts}

The VSMCs were grown in 6-well plates in DMEM containing $10 \%$ FBS. Three days after gene transfer, the VSMCs were stimulated with recombinant mouse TNF- $\alpha(10 \mathrm{ng} / \mathrm{ml})$ for $15 \mathrm{~min}, 30 \mathrm{~min}, 60 \mathrm{~min}, 6 \mathrm{~h}, 12 \mathrm{~h}, 24 \mathrm{~h}$, or $48 \mathrm{~h}$, after which the cells were washed with PBS and resuspended in cold lysis buffer containing phenylmethylsulfonyl fluoride (PMSF) and phosphorylase inhibitor. The cell lysate was then incubated on ice for $30 \mathrm{~min}$ and centrifuged at $12000 \mathrm{~g}$ for $15 \mathrm{~min}$ at $4{ }^{\circ} \mathrm{C}$. The protein concentration of the supernatant was determined using a BCA-200 protein assay kit (Beyotime, Shanghai, China). ${ }^{15}$

\section{Western Blot Analysis}

Equal amounts of proteins (20-200 $\mu \mathrm{g})$ were loaded into gels and separated by 10,12 , or $15 \%$ sodium dodecyl sulfate polyacrylamide gel electrophoresis (SDS-PAGE). The resolved proteins were then transferred onto polyvinylidene fluoride (PVDF) membranes. After blocking with 5\% non-fat milk in Tris-buffered saline with Tween (TBST) for $1 \mathrm{~h}$ at $37^{\circ} \mathrm{C}$, the blots were incubated overnight at $4{ }^{\circ} \mathrm{C}$ with primary antibodies against $\beta$-actin $(1: 1000$, mouse monoclonal, Santa Cruz Biotechnology, TX, USA), MCP-3 (1:500, goat polyclonal, Abcam, Cambridge, UK), CCR2 (1:500 rabbit polyclonal, Abcam), ERK1/2 (1:2000, rabbit polyclonal, Cell Signaling Technologies, MA, USA), p-ERK1/2 (1:2000, rabbit polyclonal, Cell Signaling Technologies), AKT (1:1000, rabbit polyclonal, Cell Signaling Technologies), or p-AKT (1:500, rabbit polyclonal, Cell Signaling Technologies) diluted in blocking buffer. The membranes were washed with TBST and probed with horseradish peroxidase-conjugated secondary antibody for $1 \mathrm{~h}$ at $37^{\circ} \mathrm{C}$. Each membrane was then washed three times in TBST, detected using chemiluminescence with an ECL detection system, and exposed to Kodak $\mathrm{X}$-OMAT AR film. All assays were repeated five times and gave similar results. The bands of the blots were visualized on the GIS Imaging System and quantified using the image processing and analysis program Image J. ERK $1 / 2$ activity is expressed as the ratio of phosphorylated ERK $1 / 2$ to total ERK1/2, AKT activity is expressed as the ratio of phosphorylated AKT to total AKT, MCP-3 expression is expressed as the ratio of MCP-3 to $\beta$-actin, and CCR2 expression is expressed as the ratio of CCR2 to $\beta$-actin.

\section{Statistical Analysis}

All experiments were performed at least four times in duplicate, with similar patterns of results. All results are expressed as the means \pm standard deviations. One-way analysis of variance was used for statistical analysis, and $P$-values less than 0.05 were considered as statistically significant.
Table 1 Tissue factor pathway inhibitor protein expression in each group $(n=5, \mu g / l)$

\begin{tabular}{lcccc}
\hline Group & First day & Third day & Fifth day & Seventh day \\
\hline Ad-MCP-3-shRNA & ND & ND & ND & ND \\
Ad-TFPI & $7.94 \pm 0.80$ & $12.46 \pm 0.56$ & $10.68 \pm 0.43$ & $9.57 \pm 0.84$ \\
Ad-EGFP & ND & ND & ND & ND \\
DMEM & ND & ND & ND & ND \\
\hline
\end{tabular}

Results are expressed as mean \pm s.d. ND indicates not detectable.

\section{RESULTS}

\section{Expression of TFPI}

The expression of TFPI protein was detected in the TFPI group on the first, third, fifth, and seventh days after gene transfer (Table 1), and the peak expression occurred on the third day. These results demonstrated that the exogenous TFPI gene was transferred into the VSMCs and has successfully expressed.

\section{Effects of MCP-3-shRNA and TFPI on the Proliferation of Vascular Smooth Muscle Cells}

To assess the effects of MCP-3-shRNA and TFPI on VSMC proliferation, we performed the BrdU ELISA. On the third day after gene transfer, cells were stimulated with recombinant mouse TNF- $\alpha(10 \mathrm{ng} / \mathrm{ml})$ for 24 or $48 \mathrm{~h}$, and then the cell culture supernatants were collected to assess VSMC proliferation using a BrdU ELISA kit. Compared with unstimulated cells, TNF- $\alpha(10 \mathrm{ng} / \mathrm{ml})$ stimulation significantly increased VSMC proliferation $(P<0.001)$. In the Ad-MCP-3-shRNA and Ad-TFPI groups, VSMC proliferation was significantly reduced compared with the levels of the Ad-EGFP and DMEM groups $(P<0.05$, Figure 1$)$.

We also evaluated VSMC proliferation using the MTT method. The optical density (OD) of the VSMCs significantly increased at 24 and $48 \mathrm{~h}$ after stimulation with TNF- $\alpha(10 \mathrm{ng} /$ $\mathrm{ml})$ when compared with unstimulated cells $(P<0.001)$. However, the VSMC OD in the Ad-MCP-3-shRNA and Ad-TFPI groups was significantly lower than those of the Ad-EGFP and DMEM groups $(P<0.001$, Figure 2$)$.

These results indicated that MCP-3 has an important role in VSMC proliferation and that TFPI can significantly inhibit VSMC proliferation induced by TNF- $\alpha$.

\section{Effect of MCP-3-shRNA and TFPI on the Expression of MCP-3 in Response to TNF- $a$ Stimulation 3 Days After Gene Transfer}

The effect of MCP-3-shRNA and TFPI on MCP-3 production in VSMCs stimulated by TNF- $\alpha$ was assessed using western blot analysis. As shown in Figure 3, at 6, 12, 24 and $48 \mathrm{~h}$ after TNF- $\alpha$ stimulation, the protein expression of MCP-3 was markedly increased after TNF- $\alpha$ stimulation compared with that of unstimulated cells $(P<0.001)$, whereas MCP-3 expression in the Ad-MCP-3-shRNA group was significantly 

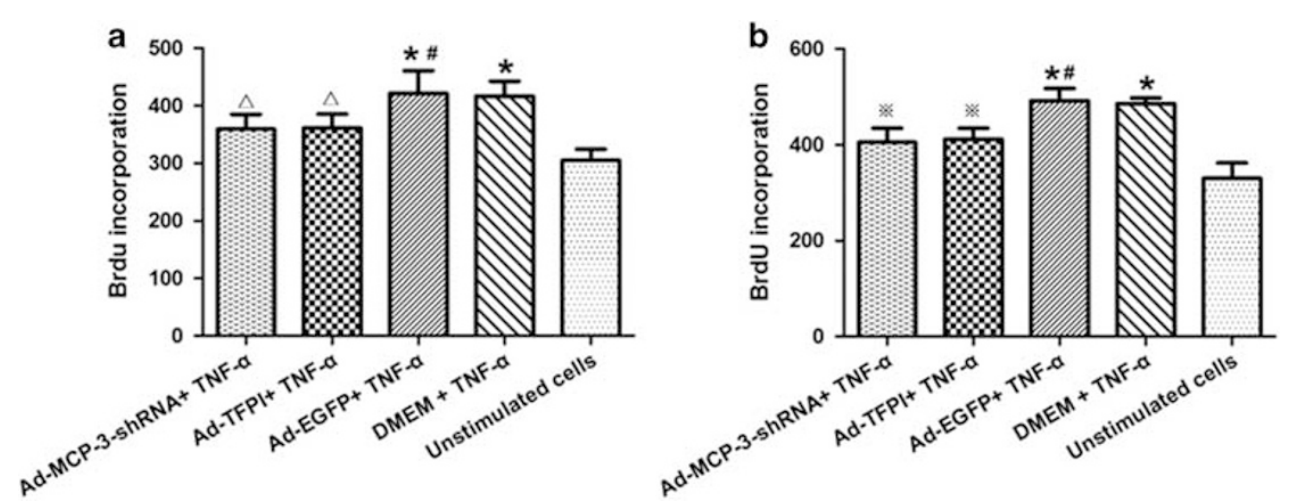

Figure 1 Effect of MCP-3-shRNA and TFPI on VSMC proliferation induced by TNF- $a$ using Brdu ELISA method. (a) TNF- $a$ stimulation for $24 \mathrm{~h}$ and (b) TNF- $a$ stimulation for $48 \mathrm{~h}$. Results are mean \pm s.d. of four experiments. ${ }^{*} P<0.001$ vs unstimulated cells, ${ }^{*} P<0.01$ vs Ad-EGFP+TNF- $a$ and DMEM + TNF- $a$ respectively, ${ }^{\Delta} P<0.05$ vs Ad-EGFP+TNF- $a$ and DMEM+TNF- $a$ respectively, ${ }^{\#} P>0.05$ vs DMEM+TNF- $a$. Brdu, bromodeoxyuridine; DMEM, Dulbecco's Modified Eagles Medium; EGFP, enhanced green fluorescent protein; MCP-3, monocyte chemotactic protein-3; TFPI, tissue factor pathway inhibitor; VSMC, vascular smooth muscle cell.
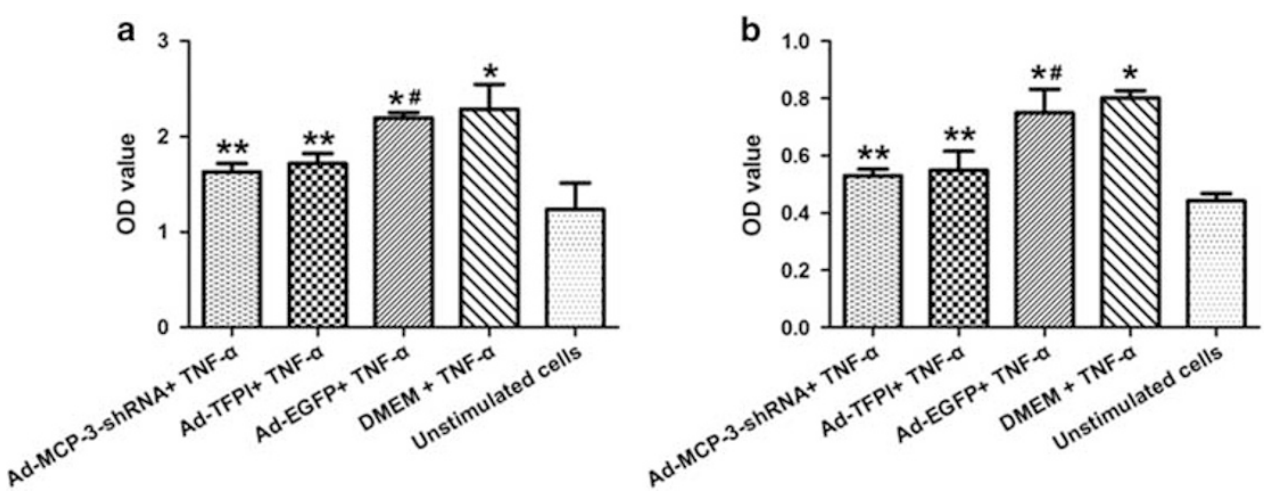

Figure 2 Effect of MCP-3-shRNA and TFPI on VSMC proliferation induced by TNF- $a$ using MTT method. (a) TNF- $a$ stimulation for $24 \mathrm{~h}$ and (b) TNF- $a$ stimulation for $48 \mathrm{~h}$. Results are mean \pm s.d. of five experiments. ${ }^{*} P<0.001$ vs unstimulated cells, ${ }^{* *} P<0.001$ vs Ad-EGFP+TNF- $a$ and DMEM+ TNF- $a$ respectively, ${ }^{\#} P>0.05$ vs DMEM+TNF- $a$. DMEM, Dulbecco's Modified Eagles Medium; EGFP, enhanced green fluorescent protein; MCP-3, monocyte chemotactic protein-3; MTT, methyl thiazolyl tetrazolium; OD, optical density; TFPI, tissue factor pathway inhibitor.

lower than those of the Ad-EGFP and DMEM groups $(P<0.001)$. In addition, at $6,12,24$ and $48 \mathrm{~h}$ after TNF- $\alpha$ stimulation, the expression of MCP-3 in the Ad-TFPI group was also markedly reduced compared with the levels of the Ad-EGFP and DMEM groups $(P<0.001)$.

The protein concentration of MCP-3 in the supernatants of cultured VSMCs was determined using ELISA. As shown in Table 2, stimulation of VSMCs with TNF- $\alpha(10 \mathrm{ng} / \mathrm{ml})$ caused a time-dependent increase in the release of MCP-3 compared with that observed in unstimulated cells $(P<0.001$ at each time point). At $6,12,24$ and $48 \mathrm{~h}$ after TNF- $\alpha$ stimulation, MCP-3 expression in the Ad-MCP-3-shRNA group was significantly inhibited compared with that in the DMEM group $(P<0.05)$, and the expression of MCP-3 in the Ad-TFPI group was also markedly reduced compared with the levels of the Ad-EGFP and DMEM groups $(P<0.05)$.

These results indicate that TFPI can significantly inhibit the TNF- $\alpha$-stimulated production of MCP-3 at multiple time points; therefore, TFPI may prevent VSMC proliferation partly through inhibiting the expression of MCP-3.

\section{Effect of MCP-3-shRNA and TFPI on the Expression of CCR2 in Response to TNF- $a$ Stimulation 3 Days After Gene Transfer}

The effect of MCP-3-shRNA and TFPI on CCR2 expression in VSMCs stimulated by TNF- $\alpha$ was determined by western blot analysis. As shown in Figure 4, the expression of CCR2 was markedly increased after TNF- $\alpha$ stimulation compared with unstimulated cells $(P<0.001)$. In contrast, at $6,12,24$ and $48 \mathrm{~h}$ after TNF- $\alpha$ stimulation, CCR2 expression in the Ad-MCP-3-shRNA group was significantly inhibited compared with those in the Ad-EGFP and DMEM group $(P<0.001)$. This result indicates that the expression of CCR2 may be affected by the decreased production of MCP-3.

At $6,12,24$ and $48 \mathrm{~h}$ after TNF- $\alpha$ stimulation, the expression of CCR2 in the Ad-TFPI group was also observably reduced compared with the levels in the Ad-EGFP and DMEM groups $(P<0.001)$. These results indicate that TFPI can markedly inhibit the expression of CCR2 stimulated by TNF- $\alpha$ at various time points after stimulation, suggesting 
a
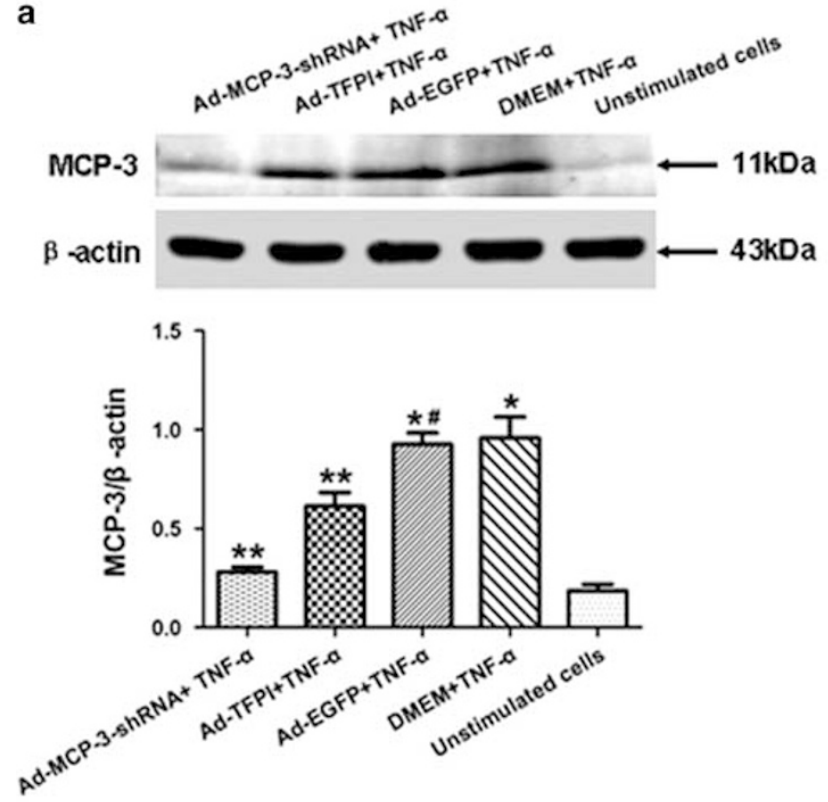

C
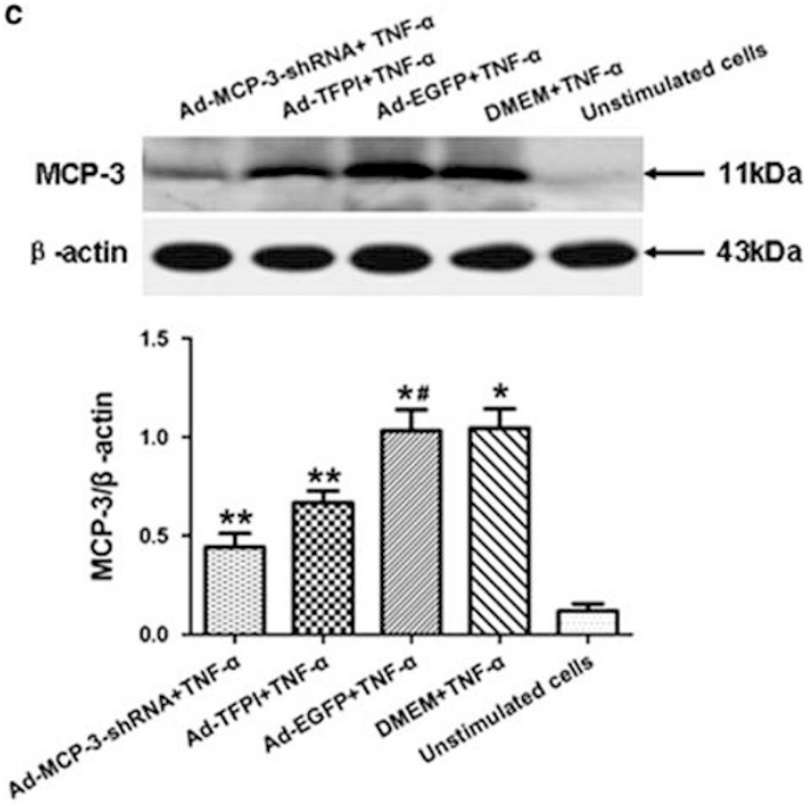

b
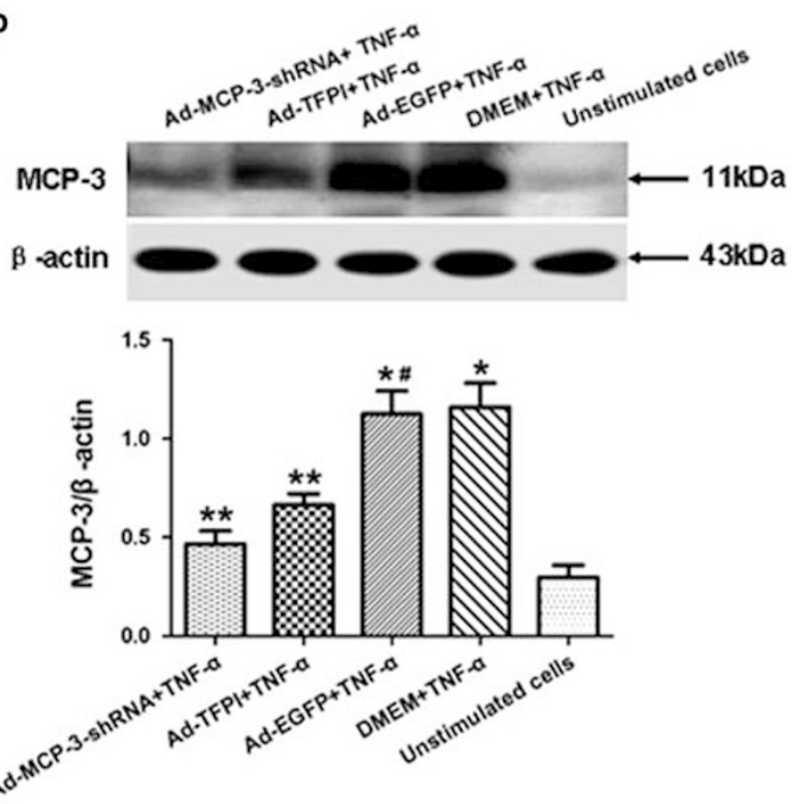

d
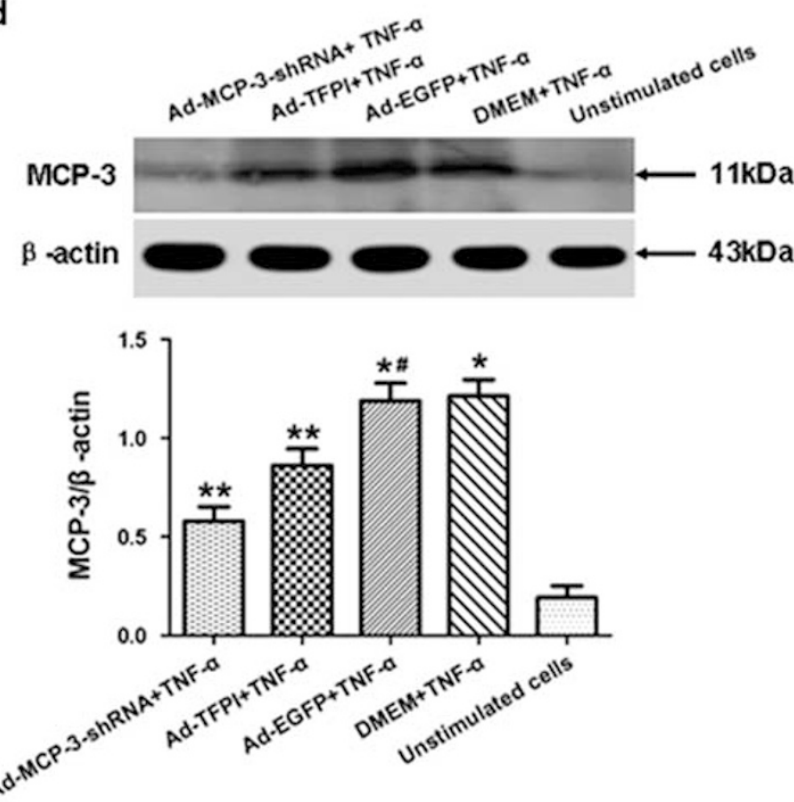

Figure 3 Effect of MCP-3-shRNA and TFPI on the expression of MCP-3 in VSMC induced by TNF- $a$. (a) TNF- $a$ stimulation for $6 \mathrm{~h}$, (b) TNF- $a$ stimulation for $12 \mathrm{~h}$, (c) TNF- $a$ stimulation for $24 \mathrm{~h}$, and (d) TNF- $a$ stimulation for $48 \mathrm{~h}$. Results are mean \pm s.d. of five experiments. ${ }^{*} P<0.001$ vs unstimulated cells, ${ }^{*} P<0.001$ vs Ad-EGFP+TNF- $a$ and DMEM+TNF- $a$, respectively, ${ }^{*} P>0.05$ vs DMEM+TNF- $a$. DMEM, Dulbecco's Modified Eagles Medium; EGFP, enhanced green fluorescent protein; MCP-3, monocyte chemotactic protein-3; TFPI, tissue factor pathway inhibitor; VSMC, vascular smooth muscle cell.

another mechanism through which TFPI might prevent VSMC proliferation.

\section{Effects of MCP-3-shRNA and TFPI on ERK1/2 Activation Induced by TNF- $a$ Stimulation 3 Days after Gene Transfer in VSMCs}

The effects of MCP-3-shRNA and TFPI on ERK1/2 activation in VSMCs stimulated by TNF- $\alpha$ were assessed using western blot method. Western blot analysis showed that ERK1/2 activation, which was visualized as increased phosphorylation of p44 and p42, was significantly increased in TNF- $\alpha(10 \mathrm{ng} /$ $\mathrm{ml}$ )-stimulated VSMCs compared with unstimulated cells $(P<0.001)$. As shown in Figure 5, at $15 \mathrm{~min}, 30 \mathrm{~min}, 60 \mathrm{~min}$ and $6 \mathrm{~h}$ after TNF- $\alpha$ stimulation, the levels of p-ERK/ERK in the Ad-MCP-3-shRNA group and Ad-TFPI group were significantly reduced compared with those in the Ad-EGFP and DMEM groups $(P<0.001)$. However, at $12 \mathrm{~h}$ after stimulation, the activation of ERK1/2 in each group has no differences $(P>0.05)$. These results confirm that the ERK1/2 signaling pathway may be involved in MCP-3-induced VSMC 
Table 2 The production of monocyte chemotactic protein-3 in each group $(n=5, \mathrm{pg} / \mathrm{ml})$

\begin{tabular}{|c|c|c|c|c|}
\hline Group & $6 \mathrm{~h}$ & $12 \mathrm{~h}$ & $24 \mathrm{~h}$ & $48 \mathrm{~h}$ \\
\hline Ad-MCP-3-shRNA+TNF- $a$ & $412.47 \pm 16.29^{a}$ & $420.06 \pm 25.36^{b}$ & $480.60 \pm 38.54^{c}$ & $521.15 \pm 47.76^{c}$ \\
\hline Ad-EGFP+TNF- $a$ & $479.05 \pm 32.66^{d}$ & $504.67 \pm 21.40^{d}$ & $605.68 \pm 29.24^{d}$ & $652.42 \pm 53.02^{d}$ \\
\hline DMEM+TNF- $a$ & $476.74 \pm 33.35^{d}$ & $501.11 \pm 47.42^{d}$ & $603.58 \pm 44.37^{d}$ & $649.22 \pm 38.06^{d}$ \\
\hline
\end{tabular}

DMEM, Dulbecco's Modified Eagles Medium; EGFP, enhanced green fluorescent protein; MCP-3, monocyte chemotactic protein-3.

Results are expressed as mean \pm s.d.

a $P<0.05$ vs Ad-EGFP+TNF- $a$ and DMEM+TNF- $a$, respectively.

${ }^{\mathrm{b}} P<0.01$ vs Ad-EGFP+TNF- $a$ and DMEM+TNF- $a$, respectively.

${ }^{c} P<0.001$ vs Ad-EGFP+TNF- $a$ and DMEM+TNF- $a$, respectively.

${ }^{\mathrm{d}} P<0.001$ vs unstimulated cells.

proliferation after TNF- $\alpha$ stimulation and this inhibitory effect on ERK1/2 activation may be among the mechanisms by which TFPI prevents VSMC proliferation.

\section{Effects of MCP-3-shRNA and TFPI on AKT Activation Induced by TNF- $a$ Stimulation 3 Days After Gene Transfer in VSMCs}

The effects of MCP-3-shRNA and TFPI on AKT activation in VSMCs stimulated by TNF- $\alpha$ were assessed using western blot method. Western blot analysis showed that AKT activation was significantly increased in TNF- $\alpha(10 \mathrm{ng} / \mathrm{ml})$-stimulated VSMCs compared with unstimulated cells $(P<0.001)$. As shown in Figure 6, at $15 \mathrm{~min}, 30 \mathrm{~min}, 60 \mathrm{~min}, 6 \mathrm{~h}, 12 \mathrm{~h}$ and $24 \mathrm{~h}$ after TNF- $\alpha$ stimulation, the levels of $\mathrm{p}$-AKT/AKT in the Ad-MCP-3-shRNA group and Ad-TFPI group were significantly inhibited compared with those in the Ad-EGFP and DMEM groups $(P<0.01)$. These results confirm that the PI3K/AKT signaling pathways may be involved in MCP-3induced VSMC proliferation after TNF- $\alpha$ stimulation and the inhibition of AKT phosphorylation by TFPI may participate in VSMC proliferation.

\section{DISCUSSION}

The most important findings of the present study are that the delivery of both an adenovirus containing an shRNA that targets mouse MCP-3 and an adenovirus containing the human TFPI gene could significantly prevent VSMC proliferation induced by TNF- $\alpha$, which is known to be involved in atherosclerosis and intimal hyperplasia. Furthermore, we show that TFPI may exert this effect by inhibiting the expression of MCP-3 and of its receptor CCR2. We also report for the first time that TFPI can inhibit the phosphorylation of ERK1/2 and AKT, which are associated with MCP-3-induced VSMC proliferation. These results indicate that MCP-3 is a major contributor to VSMC proliferation, and TFPI may exert its anti-proliferative effects at least partly through inhibiting the MCP-3/CCR2 pathway and therefore may have an important role in atherosclerosis and intimal hyperplasia.
Atherosclerosis is a progressive inflammatory disease in which inflammatory cells and VSMCs are important sources of cytokines that control the migration, proliferation, and activation of VSMCs, leading to intimal hyperplasia. In recent years, recognition of the importance of inflammation in atherosclerosis and intimal hyperplasia has increased. VSMC proliferation has a key role in atherosclerosis and the intimal hyperplasia caused by inflammation and can be induced to produce various inflammatory cytokines, including chemokines. ${ }^{1,3,18,19}$ Recent studies have implied that the process of proliferation is regulated by the production of chemokines in vascular cells. ${ }^{20}$ Several chemokines are involved in atherosclerosis and intimal hyperplasia, and operate at least partly through different mechanisms and at different steps in the disease process. ${ }^{21,22}$ The largest family of these factors is the proinflammatory CC chemokines, of which the most thoroughly characterized member is MCP-1. MCP-1 has a pivotal role in the recruitment of monocytes from the blood into early atherosclerotic lesions, as well as in the development of intimal hyperplasia via VSMC activation. ${ }^{8,23}$ In vascular injury models, anti-MCP-1 gene therapy can reduce neointimal hyperplasia after stent injury, perivascular injury, and vein bypass grafting. ${ }^{24}$

MCP-3, which is also a member of the CC chemokine subfamily, is known to share some key biological features with MCP-1. MCP-3 has 71\% amino acid identity to MCP-1 and has previously been shown to be induced in endothelial cells and VSMCs after cytokine stimulation. ${ }^{25}$ However, few reports have addressed the potential function of MCP-3 in VSMCs and vascular pathology. Wang et al ${ }^{25}$ demonstrated that MCP-3 mRNA expression has been significantly induced in the carotid artery after balloon angioplasty and in cultured rat VSMCs by various stimuli, such as TNF- $\alpha$. This trend of MCP-3 expression was consistent with that of MCP-1. Lötzer et $a l^{26}$ reported that mouse VSMCs were involved in the formation of tertiary lymphoid tissue in atherosclerosis through an increase in the mRNA levels of chemokines such as MCP-3. All of these data indicate that MCP-3 has an important role in atherosclerosis and restenosis after vascular injury, especially in VSMCs. To better clarify this point, we 
a
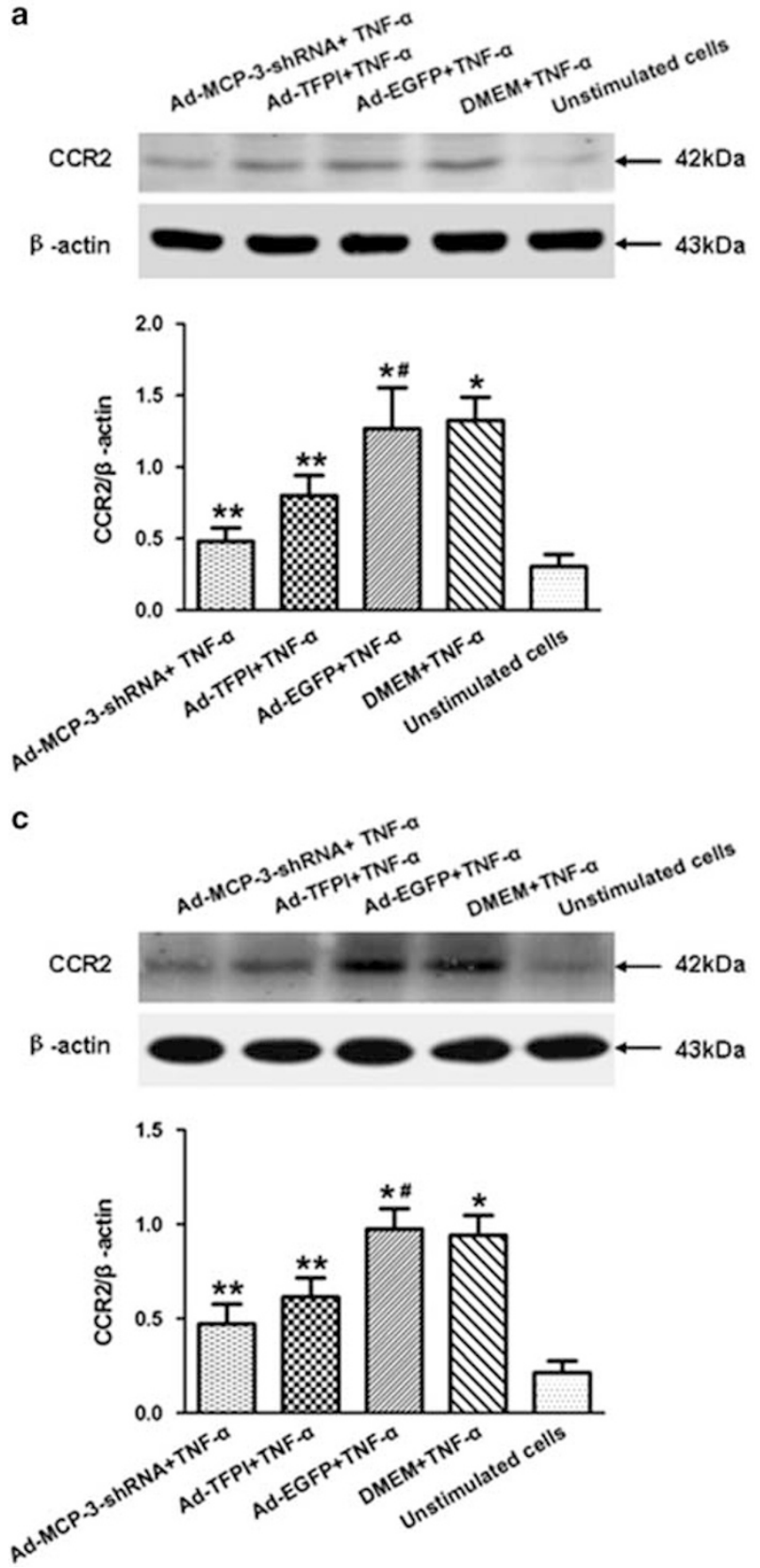

b
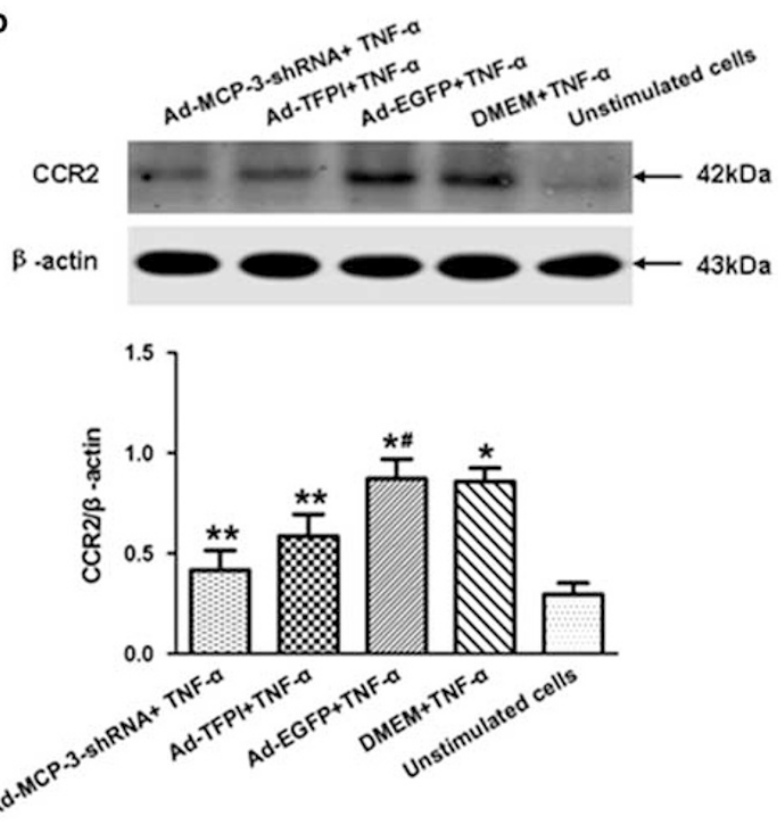

d
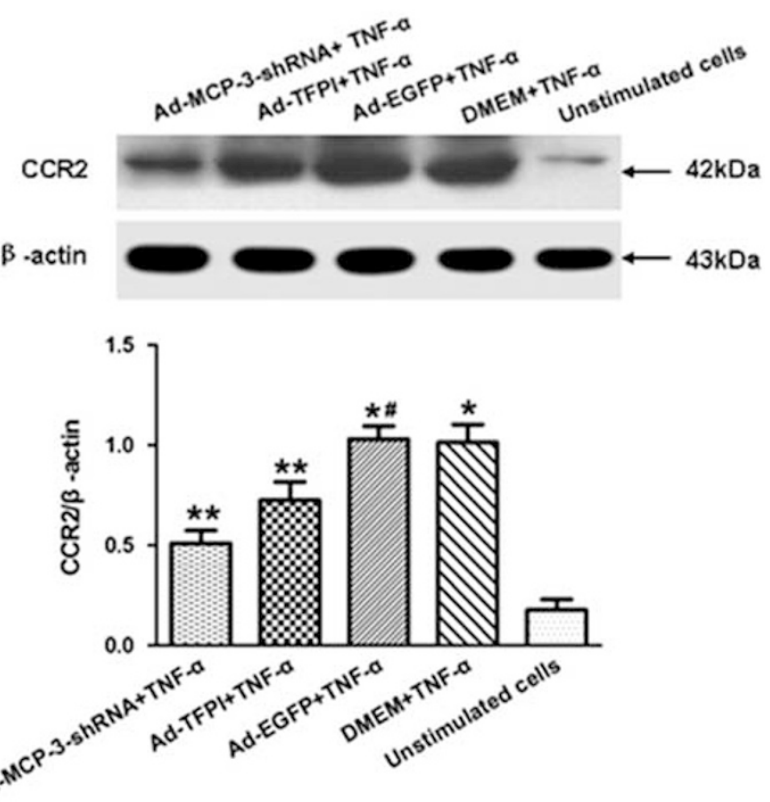

Figure 4 Effect of MCP-3-shRNA and TFPI on the expression of CCR2 in VSMC induced by TNF- $a$. (a) TNF- $a$ stimulation for $6 \mathrm{~h}$, (b) TNF- $a$ stimulation for $12 \mathrm{~h}$, (c) TNF- $a$ stimulation for $24 \mathrm{~h}$, and (d) TNF- $a$ stimulation for $48 \mathrm{~h}$. Results are mean \pm s.d. of five experiments. ${ }^{*} P<0.001$ vs unstimulated cells, ${ }^{*} P<0.001$ vs Ad-EGFP+TNF- $a$ and DMEM+TNF- $a$, respectively, ${ }^{*} P>0.05$ vs DMEM+TNF- $a$. CCR2, CC chemokine receptor 2; DMEM, Dulbecco's Modified Eagles Medium; EGFP, enhanced green fluorescent protein; MCP-3, monocyte chemotactic protein-3; TFPI, tissue factor pathway inhibitor; VSMC, vascular smooth muscle cell.

Figure 5 Effect of MCP-3-shRNA and TFPI on ERK1/2 activation induced by TNF- $a$. (a) TNF- $a$ stimulation for 15 min, (b) TNF- $a$ stimulation for 30 min, (c) TNF- $a$ stimulation for $60 \mathrm{~min}$, (d) TNF- $a$ stimulation for $6 \mathrm{~h}$, and (e) TNF- $a$ stimulation for $12 \mathrm{~h}$. Results are mean \pm s.d. of five experiments. ${ }^{*} P<0.001$ vs unstimulated cells, ${ }^{* *} P<0.001$ vs Ad-EGFP+TNF- $a$ and DMEM+TNF- $a$ respectively, ${ }^{\circ} P>0.05$ vs Ad-EGFP+TNF- $a$ and DMEM+TNF- $a$, respectively, ${ }^{\#} P>0.05$ vs DMEM+TNF- $a$. DMEM, Dulbecco's Modified Eagles Medium; EGFP, enhanced green fluorescent protein; MCP-3, monocyte chemotactic protein-3; TFPI, tissue factor pathway inhibitor; VSMC, vascular smooth muscle cell. 
a

a
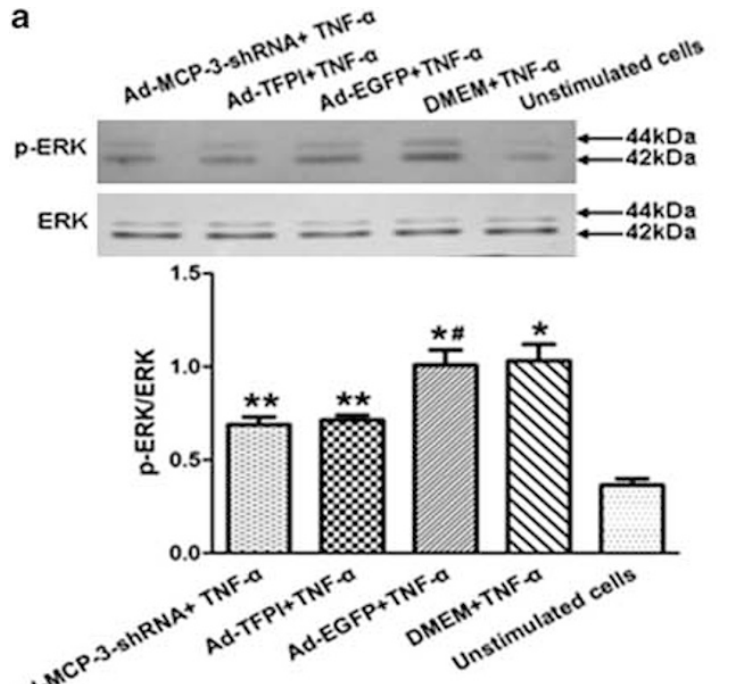

C
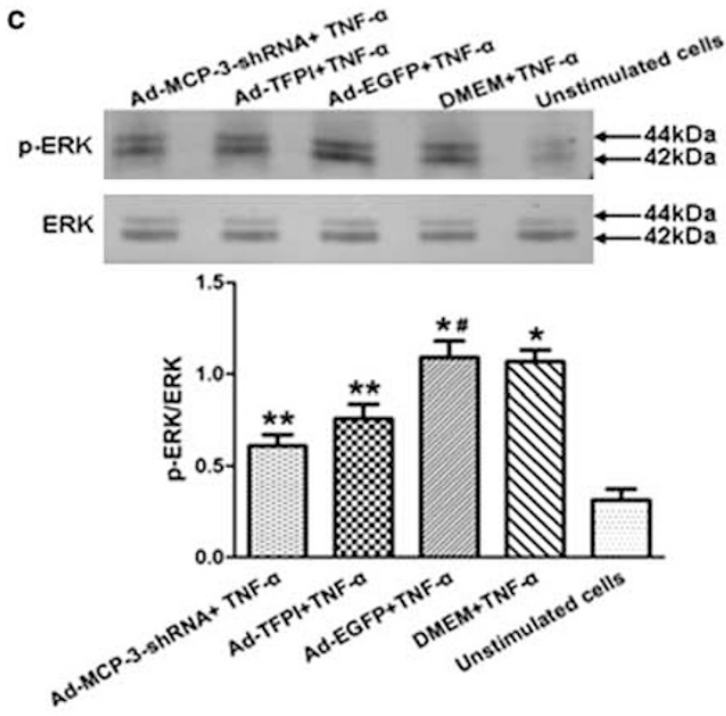

e
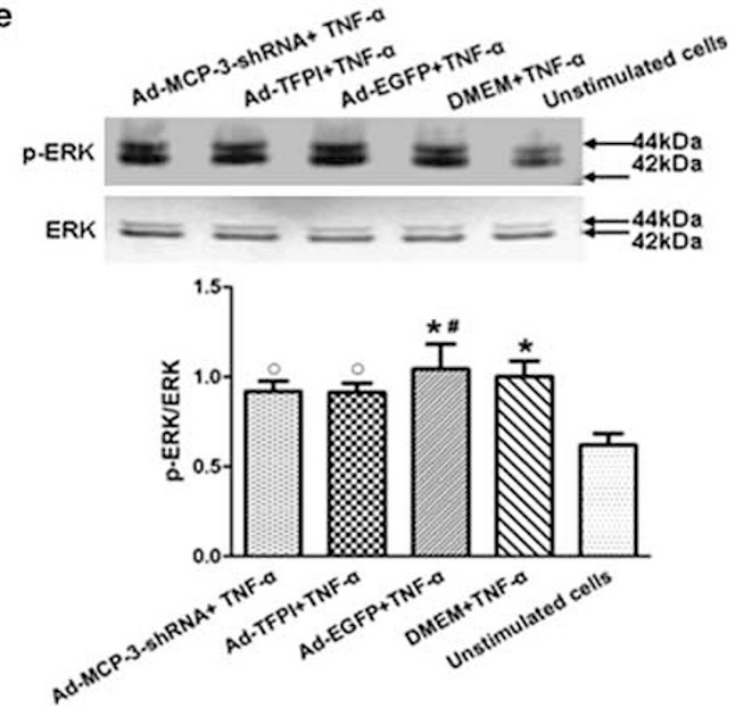

b
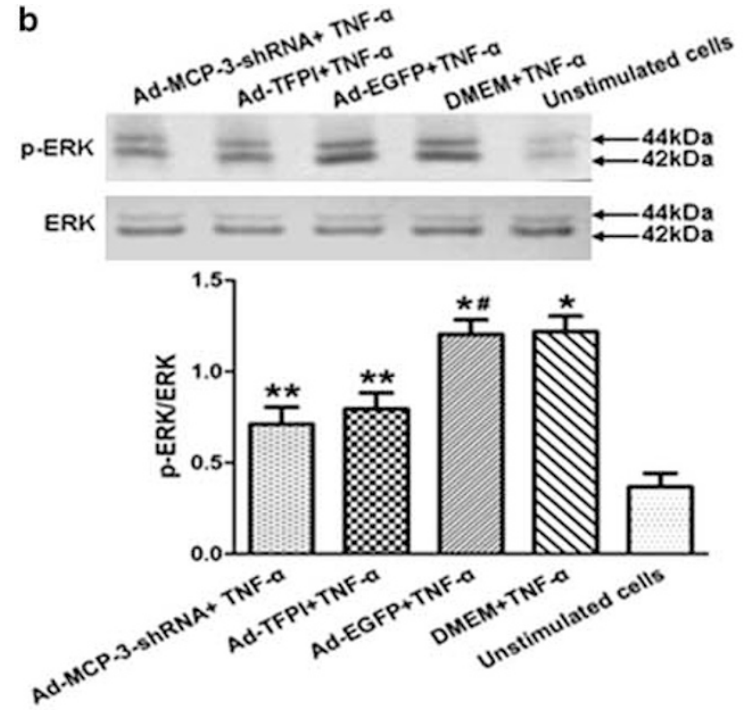

d

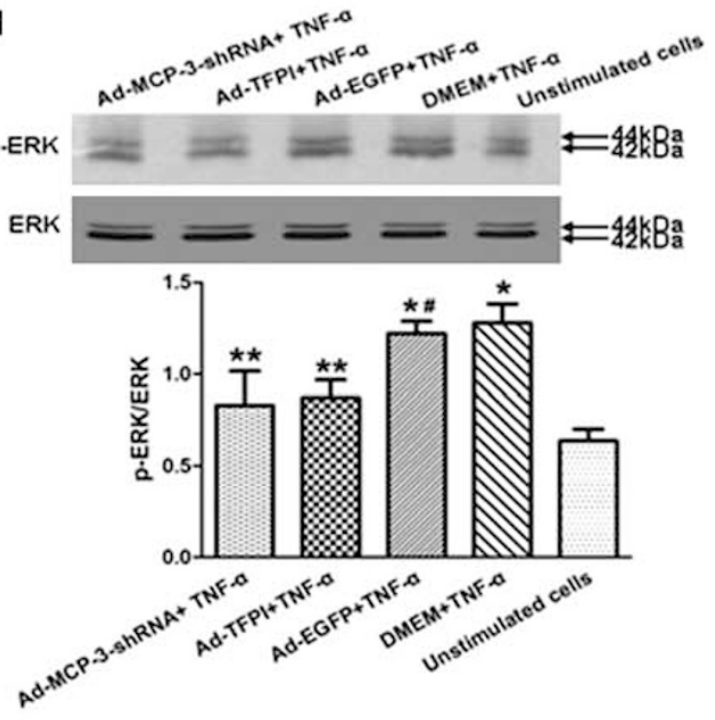


first constructed an adenovirus containing mouse MCP-3shRNA (Ad-MCP-3-shRNA) and infected cultured mouse VSMCs with this virus in vitro to silence MCP-3 selectively and efficiently using the RNAi method. Then, we stimulated the cells with TNF- $\alpha$ on the third day after gene transfer. The results showed that the level of MCP-3 expression in the Ad-MCP-3-shRNA group was significantly lower than those in the Ad-EGFP and DMEM groups after stimulation for 6, 12, 24 and $48 \mathrm{~h}$. The proliferation of VSMCs in the Ad-MCP-3-shRNA group was also markedly inhibited compared with the Ad-EGFP and DMEM groups after stimulation. Based on these findings, we can conclude that VSMC proliferation is inhibited when the expression of MCP-3 is decreased. Therefore, it is reasonable to speculate that MCP-3 has an important role in VSMC proliferation and may be a probable target for the treatment of VSMC proliferation.

TFPI is an endogenous anticoagulant protein and is the only substance known to regulate the TF-dependent coagulation pathway. TFPI, which contains three Kunitz domains, inhibits TF activity by forming a quaternary complex through two steps. The Kunitz II domain first binds to factor $\mathrm{Xa}$, and then the Kunitz I domain binds to the TF/FVIIa complex. Except anticoagulation, TFPI was shown to reduce neointimal hyperplasia in local injured arteries by inhibiting VSMC proliferation and migration in many in vivo studies. ${ }^{27,28} \mathrm{We}$ also found that TFPI gene transfer could induce VSMC apoptosis by preventing the activation of JAK-2/STAT-3 pathway, ${ }^{15,16}$ which is also involved in VSMC proliferation. However, little is known about the effect of TFPI on VSMC proliferation. Kamikubo et $a l^{27}$ have found that h-rTFPI exhibits inhibitory activity toward hSMC proliferation, but Atsuchi et $a l^{29}$ detected no rTFPI 3 days after irrigation. In our previous study, we found that the peak expression of the TFPI gene carried by adenovirus occurred on the third day after gene transfer and there were not enough TFPI protein generated to inhibit the expression of MCP-3 induced by TNF- $\alpha$ immediately after gene transfer. ${ }^{17}$ Based on these results, in this study, we used an adenoviral vector, which leads to long-term expression of the target gene in cells, to transfer the TFPI gene into mouse VSMCs cultured in vitro. We then stimulated the cells with TNF- $\alpha$ on the third day after gene transfer to observe the effect of TFPI on the proliferation of VSMCs. The results showed that the VSMC proliferation in the Ad-TFPI group was markedly inhibited compared with those in the Ad-EGFP and DMEM groups. These results indicate that overexpression of TFPI exhibits inhibitory activity toward the growth of VSMCs in addition to its anticoagulant activity. Therefore, TFPI may be a promising treatment for preventing atherosclerosis and intimal hyperplasia.

Whether inflammation, which also leads to VSMC proliferation, is involved in the anti-proliferative effect of TFPI has not yet been investigated in detail. Only two reports currently exist regarding this topic. Nakamura et $a b^{30}$ demonstrated that macrophage infiltration was suppressed 7 days after rTFPI delivery. Also of interest is the finding by
Kopp et al, ${ }^{12}$ who transferred Ad-TFPI into local injured rabbit femoral arteries and found that MCP-1 expression in the neointimal hyperplasia was markedly decreased in the TFPI-treated arteries, but the mechanism was not clear. To clarify the mechanism underlying the inhibitory role of TFPI in VSMC proliferation, we also stimulated cells with TNF- $\alpha$ on the third day after gene transfer and examined the expression of MCP-3 in the Ad-TFPI group. After stimulation for $6,12,24$ and $48 \mathrm{~h}$, the production of MCP-3 in the Ad-TFPI group was significantly lower than those in the Ad-EGFP and DMEM groups. These data are consistent with our previous result in rat VSMCs and suggest that TFPI might prevent macrophage accumulation and inhibit VSMC proliferation by reducing the production of proinflammatory factor MCP-3 and thus inhibit intimal proliferation.

Chemokine receptors belong to $G$ protein-coupled cell surface receptors. The effects of MCPs are mediated mainly through the activation of their cognate receptor, CCR2.${ }^{31}$ There is evidence of CCR2 expression on endothelial cells and VSMCs of rat and apoE $-/$ - mice, suggesting that CCR2 may not only mediate monocyte infiltration but may also participate in endothelial cell and VSMC migration and proliferation during intimal hyperplasia and atherosclerosis. ${ }^{20,24,32}$ It has been reported that an antibody blocking CCR2 provides significant protection against in-stent stenosi ${ }^{33}$ and a method targeted deletion of CCR $2^{34}$ reduces atherosclerosis in mice models. The effect of MCP-3 is also mainly mediated by its interaction with chemokine receptors expressed on VSMCs. ${ }^{35}$ Like most chemokine receptors, CCR2 is activated by multiple agonists, including MCP-3. ${ }^{36}$ Furthermore, a MCP-3-/mouse strain was generated and was used to demonstrate that MCP-3 serves as an important CCR2 ligand that enhances in vivo monocyte recruitment. ${ }^{37}$ In the present study, we first transferred Ad-MCP-3-shRNA into cultured mouse VSMCs and then stimulated those cells with TNF- $\alpha$ on the third day after gene transfer. The data showed that after stimulation for $6,12,24$ and $48 \mathrm{~h}$, the expression of CCR2 induced by TNF- $\alpha$ was increased compared with that in the unstimulated cells; however, along with the decreasing production of MCP-3, the level of CCR2 expression in the Ad-MCP-3-shRNA group was significantly lower than those in the Ad-EGFP and DMEM groups. We also infected cultured VSMCs with Ad-TFPI and then stimulated those cells with TNF- $\alpha$. The results indicated that the level of CCR2 expression in the Ad-TFPI group was significantly reduced compared with those in the Ad-EGFP and DMEM groups. However, it remains unclear whether TFPI inhibits the expression of CCR2 directly or through reducing the production of MCP-3, which can induce CCR2 expression. This should be clarified in future research.

Additionally, Shahrara et $a^{38}$ have found that CCR2 tyrosine phosphorylation was associated with the JAK/STAT-3 pathway at different stages of rat adjuvant-induced arthritis, as well as with macrophage and endothelial cell infiltration. In our previous study, we demonstrated that TFPI gene transfer induced VSMC apoptosis by suppressing the phosphorylation 
a
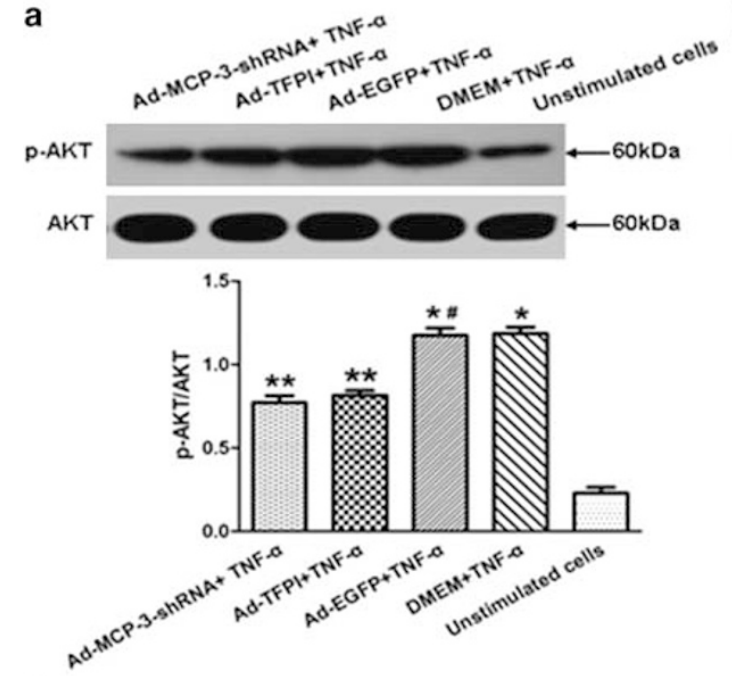

C
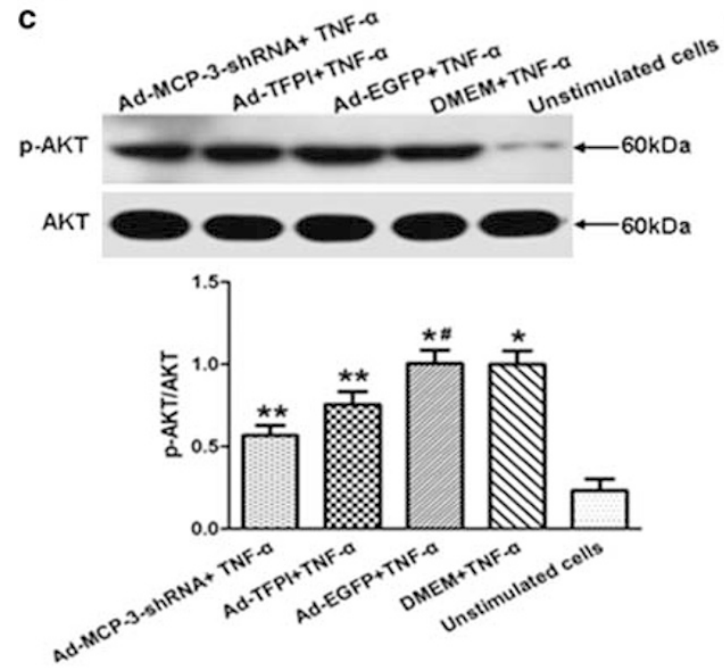

e

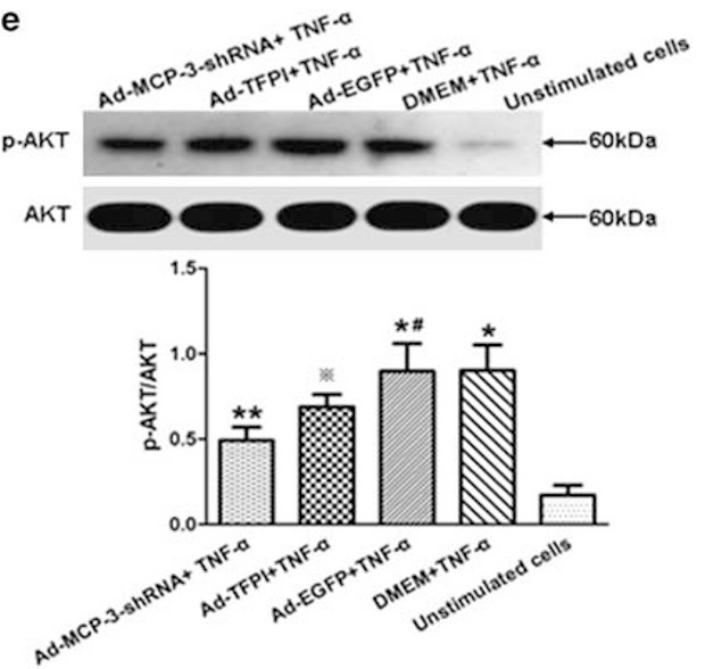

b

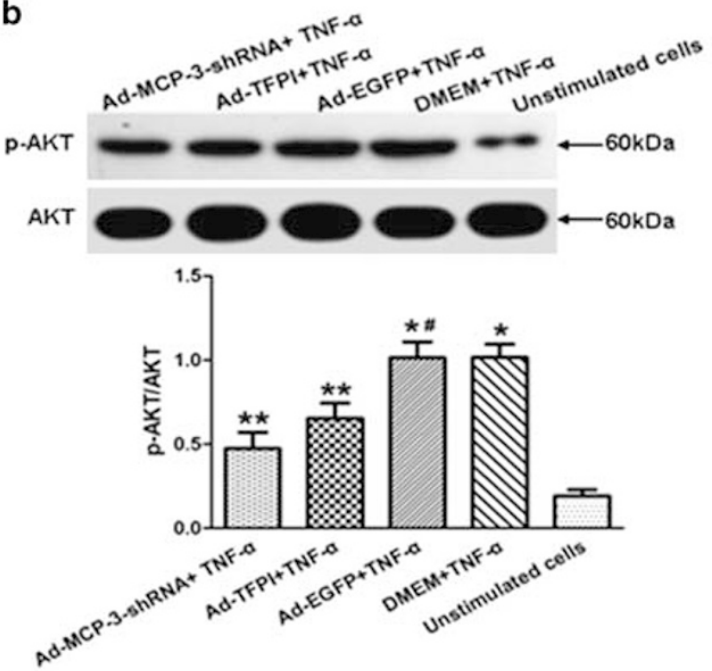

d
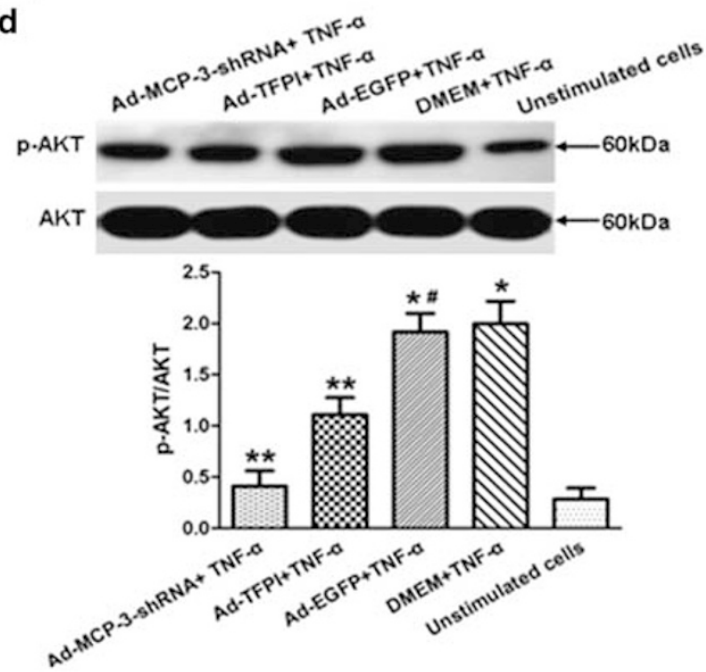

f
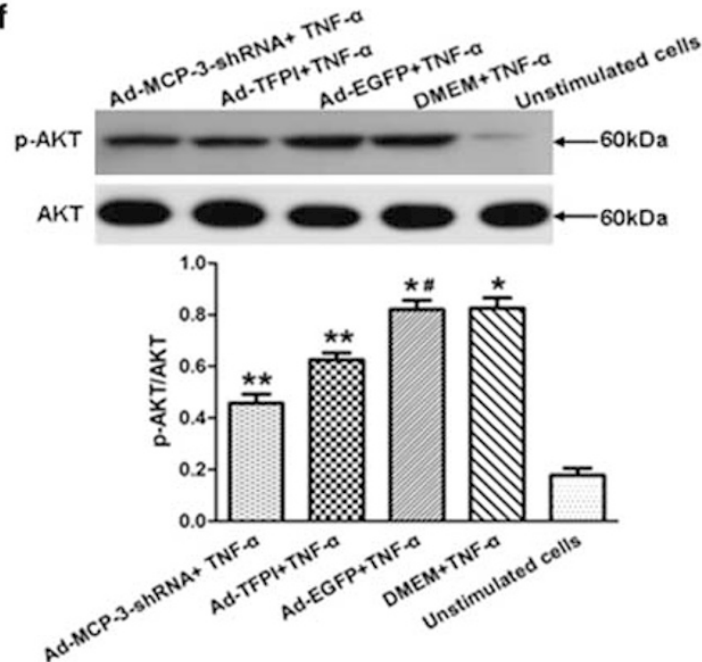

Figure 6 Effect of MCP-3-shRNA and TFPI on AKT activation induced by TNF- $a$. (a) TNF- $a$ stimulation for 15 min, (b) TNF- $a$ stimulation for 30 min,

(c) TNF- $a$ stimulation for $60 \mathrm{~min}$, (d) TNF- $a$ stimulation for $6 \mathrm{~h}$, (e) TNF- $a$ stimulation for $12 \mathrm{~h}$, and (f) TNF- $a$ stimulation for $24 \mathrm{~h}$. Results are mean $\pm \mathrm{s}$.d. of five experiments. ${ }^{*} P<0.001$ vs unstimulated cells, ${ }^{* *} P<0.001$ vs Ad-EGFP+TNF- $a$ and DMEM+TNF- $a$, respectively, ${ }^{*} P<0.01$ vs Ad-EGFP+TNF- $a$ and DMEM + TNF- $a$, respectively, ${ }^{\#} P>0.05$ vs DMEM+TNF- $a$. DMEM, Dulbecco's Modified Eagles Medium; EGFP, enhanced green fluorescent protein; MCP-3, monocyte chemotactic protein-3; TFPI, tissue factor pathway inhibitor. 
of JAK-2/STAT-3 signaling pathway, which also participates in cell proliferation. ${ }^{16}$ Based on this evidence, we propose that TFPI might block phosphorylation of the JAK-2/STAT-3 pathway by regulating the MCP-3/CCR2 pathway and eventually inhibit VSMC proliferation induced by TNF- $\alpha$.

Previous work has demonstrated the involvement of the ERK1/2 MAPK cascade and the PI3K/AKT signaling pathway in VSMC proliferation. ${ }^{39}$ In the present study, we first transferred Ad-MCP-3-shRNA into cultured mouse VSMCs and then stimulated cells with TNF- $\alpha$ on the third day after gene transfer. The data showed that after stimulation for $15 \mathrm{~min}, 30 \mathrm{~min}, 60 \mathrm{~min}$, or $6 \mathrm{~h}$, the activation of ERK1/2 and AKT in the Ad-MCP-3-shRNA group was significantly inhibited compared with those in the Ad-EGFP and DMEM groups. At $12 \mathrm{~h}$ after TNF- $\alpha$ stimulation, the activation of ERK1/2 did not differ among the groups, but at 12 and $24 \mathrm{~h}$ after TNF- $\alpha$ stimulation, the level of p-AKT/AKT in the Ad-MCP-3-shRNA group was significantly suppressed compared with those in the Ad-EGFP and DMEM groups. These data are consistent with the results from Maddaluno et al and proved the mechanism of MCP-3 on inducing VSMC proliferation by increasing the phosphorylation of ERK1/2 and AKT. We also transferred Ad-TFPI into cultured VSMCs in vitro and stimulated cells with TNF- $\alpha$ on the third day after gene transfer. The results showed that after stimulation for $15 \mathrm{~min}, 30 \mathrm{~min}, 60 \mathrm{~min}$, or $6 \mathrm{~h}$, the activation of ERK1/2 and AKT in the Ad-TFPI group was significantly inhibited compared with those in the Ad-EGFP and DMEM groups. At $12 \mathrm{~h}$ after TNF- $\alpha$ stimulation, the activation of ERK1/2 was similar in each group, but the level of p-AKT/AKT in the Ad-TFPI group was significantly lower than those in the Ad-EGFP and DMEM groups at 12 and $24 \mathrm{~h}$ after TNF- $\alpha$ stimulation. These results confirm that the ERK1/2 and PI3K/ AKT signaling pathways may be involved in the inhibitory effect of TFPI on VSMC proliferation after TNF- $\alpha$ stimulation. Therefore, targeting these two signaling pathways may provide a novel therapeutic avenue for TFPI in preventing atherosclerosis and neointimal hyperplasia.

In conclusion, based on the findings of the present study, we show that Ad-MCP-3-shRNA prevents VSMC proliferation by silencing the expression of MCP-3 induced by TNF- $\alpha$ and therefore inhibiting the phosphorylation of the ERK1/2 and PI3K/AKT signaling pathways, confirming the importance of MCP-3 in VSMC proliferation. Our results also represent the first demonstration of TFPI-mediated inhibition on TNF- $\alpha$ induced VSMC proliferation by suppressing the expression of MCP-3 and CCR2 and then the phosphorylation of the ERK 1/2 and PI3K/AKT signaling pathways. Our findings will lead to a greater understanding of the molecular mechanism by which TFPI inhibits VSMC proliferation. Furthermore, targeting the MCP-3/CCR2 pathway by overexpressing TFPI may be a new therapeutic avenue for the treatment of intimal hyperplasia and atherosclerosis.

This study provides convincing evidence that clarifies the effect of the proinflammatory factor MCP-3 in promoting
VSMC proliferation. Further experiments also characterized the inhibitory effect of TFPI on VSMC proliferation and identified that this effect might be mediated partly through interfering with the MCP-3/CCR2 pathway and then suppression of the ERK1/2 and PI3K/AKT signaling pathway phosphorylation. Based on these results, we presume that TFPI gene transfer may be a new, safe, and effective therapeutic tool for treating atherosclerosis and intimal hyperplasia.

\section{ACKNOWLEDGMENTS}

This work was supported by the Natural Science Foundation of China (No. 81200143, No. 81200235), the Natural Science Fund of Heilongjiang projects (No. QC2012C015), Heilongjiang Traditional Chinese Medicine Scientific

Research Project (ZHY12-W035), the Talent Innovation Foundation of Harbin Institute of Technology Bureau (2012RFXXS008), Postdoctoral Research Start Fund of Heilongjiang Province (LBH-Q1 1061) and the Foundation of the First Affiliated Hospital of Harbin Medical University (2015B002).

\section{DISCLOSURE/CONFLICT OF INTEREST}

The authors declare no conflict of interest.

1. Al-Bannawi A, Al-Wesebai K, Taha $\mathrm{S}$ et al. Chlamydia pneumoniae induces chemokine expression by platelets in patients with atherosclerosis. Med Princ Pract 2011;20:438-443.

2. Dzau VJ, Braun-Dullaeus RC, Sedding DG. Vascular proliferation and atheroscle- rosis: new perspectives and therapeutic strategies. Nat Med 2002;8:1249-1256.

3. Andres V, Pello OM, Silvestre-Roig C. Macrophage proliferation and apoptosis in atherosclerosis. Curr Opin Lipidol 2012;23:429-438.

4. Moore KJ, Tabas I. Macrophages in the pathogenesis of atherosclerosis. Cell 2011;145:341-355.

5. Rosenfeld ME. Inflammation and atherosclerosis: direct versus indirect mechanisms. Curr Opin Pharmacol 2013;13:154-160.

6. Liu XL, Zhang PF, Ding SF et al. Local gene silencing of monocyte chemoattractant protein-1 prevents vulnerable plaque disruption in apolipoprotein E-knockout mice. PLoS One 2012;7:e33497.

7. Tsou CL, Peters W, Si Y et al. Critical roles for CCR2 and MCP-3 in monocyte mobilization from bone marrow and recruitment to inflammatory sites. J Clin Invest 2007;117:902-909.

8. Schober A. Chemokines in vascular dysfunction and remodeling. Arterioscler Thromb Vasc Biol 2008;28:1950-1959.

9. An SJ, Jung UJ, Choi MS et al. Functions of monocyte chemotactic protein-3 in transgenic mice fed a high-fat, high-cholesterol diet. J Microbiol Biotechnol 2013;23:405-413.

10. Maddaluno M, Di Lauro M, Di Pascale A et al. Monocyte chemotactic protein-3 induces human coronary smooth muscle cell proliferation. Atherosclerosis 2011;217:113-119.

11. Lwaleed BA, Bass PS. Tissue factor pathway inhibitor: structure, biology and involvement in disease. J Pathol 2006;208:327-339.

12. Kopp CW, Holzenbein T, Steiner S et al. Inhibition of restenosis by tissue factor pathway inhibitor: in vivo and in vitro evidence for suppressed monocyte chemoattraction and reduced gelatinolytic activity. Blood 2004;103:1653-1661.

13. Yin $X$, Yutani $C$, Ikeda $Y$ et al. Tissue factor pathway inhibitor gene delivery using HVJ-AVE liposomes markedly reduces restenosis in atherosclerotic arteries. Cardiovasc Res 2002;56:454-463.

14. Yin X, Fu Y, Yutani C et al. HVJ-AVE liposome-mediated Tissue Factor Pathway Inhibitor (TFPI) gene transfer with recombinant TFPI (rTFPI) irrigation attenuates restenosis in atherosclerotic arteries. Int J Cardiol 2009;135:245-248.

15. Fu Y, Zhang Z, Zhang G et al. Adenovirus-mediated gene transfer of tissue factor pathway inhibitor induces apoptosis in vascular smooth muscle cells. Apoptosis 2008;13:634-640.

16. Fu Y, Zhao Y, Liu Y et al. Adenovirus-mediated tissue factor pathway inhibitor gene transfer induces apoptosis by blocking the phosphorylation of JAK-2/STAT-3 pathway in vascular smooth muscle cells. Cell Signal 2012;24:1909-1917. 
17. Zhao Y, Fu Y, Hu J et al. The effect of tissue factor pathway inhibitor on the expression of monocyte chemotactic protein-3 and IKB- $a$ stimulated by tumour necrosis factor- $\alpha$ in cultured vascular smooth muscle cells. Arch Cardiovasc Dis 2013;106:4-11.

18. Marx SO, Totary-Jain H, Marks AR. Vascular smooth muscle cell proliferation in restenosis. Circ Cardiovasc Interv 2011;4:104-111.

19. Libby P, Ridker PM, Hansson GK. Inflammation in atherosclerosis: from pathophysiology to practice. J Am Coll Cardiol 2009;54:2129-2138.

20. Zhang S, Wang $X$, Zhang $L$ et al. Characterization of monocyte chemoattractant proteins and CC chemokine receptor 2 expression during atherogenesis in apolipoprotein E-null mice. J Atheroscler Thromb 2011;18:846-856.

21. Chan CT, Moore JP, Budzyn $\mathrm{K}$ et al. Reversal of vascular macrophage accumulation and hypertension by a CCR2 antagonist in deoxycorticosterone/salt -treated mice. Hypertension 2012;60:1207-1212.

22. Aukrust P, Halvorsen B, Yndestad A et al. Chemokines and cardiovascular risk. Arterioscler Thromb Vasc Biol 2008;28:1909-1919.

23. Yadav A, Saini V, Arora S. MCP-1: chemoattractant with a role beyond immunity: a review. Clin Chim Acta 2010;411:1570-1579.

24. Ali ZA, Bursill CA, Douglas G et al. CCR2-mediated antiinflammatory effects of endothelial tetrahydrobiopterin inhibit vascular injuryinduced accelerated atherosclerosis. Circulation 2008;118:S71-S77.

25. Wang X, Li X, Yue TL et al. Expression of monocyte chemotactic protein-3 mRNA in rat vascular smooth muscle cells and in carotid artery after balloon angioplasty. Biochim Biophys Acta 2000;1500: 41-48.

26. Lötzer K, Döpping S, Connert S et al. Mouse aorta smooth muscle cells differentiate into lymphoid tissue organizer-like cells on combined tumor necrosis factor receptor-1/lymphotoxin beta-receptor NF-kappaB signaling. Arterioscler Thromb Vasc Biol 2010;30:395-402.

27. Kamikubo $Y$, Nakahara $Y$, Takemoto $S$ et al. Human recombinant tissue factor pathway inhibitor prevents the proliferation of cultured human neonatal aortic smooth muscle cells. FEBS Lett 1997;407:116-120.

28. Sato $Y$, Asada $Y$, Marutsuka $K$ et al. Tissue factor pathway inhibitor inhibits aortic smooth muscle cell migration induced by tissue factor/ factor Vlla complex. Thromb Haemost 1997;78:1138-1141.
29. Atsuchi $\mathrm{N}$, Nishida $\mathrm{T}$, Marutsuka $\mathrm{K}$ et al. Combination of a brief irrigation with tissue factor pathway inhibitor (TFPI) and adenovirus mediated local TFPI gene transfer additively reduces neointima formation in balloon-injured rabbit carotid arteries. Circulation 2001;103:570-575.

30. Nakamura Y, Nakamura K, Ohta K et al. Anti-inflammatory effects of longlasting locally-delivered human recombinant tissue factor pathway inhibitor after balloon angioplasty. Basic Res Cardiol 2002;97:198-205.

31. Fenyo IM, Gafencu AV. The involvement of the monocytes/macrophages in chronic inflammation associated with atherosclerosis. Immunobiology 2013;218:1376-1384.

32. Grassia G, Maddaluno M, Guglielmotti $A$ et al. The anti-inflammatory agent bindarit inhibits neointima formation in both rats and hyperlipidaemic mice. Cardiovasc Res 2009;84:485-493.

33. Horvath C, Welt FGP, Nedelman $M$ et al. Targeting CCR2 or CD18 inhibits experimental in-stent restenosis in primates. Inhibitory potential depends on type of injury and leukocytes targeted. Circ Res 2002;90:488-494.

34. Boring L, Gosling J, Cleary $M$ et al. Decreased lesion formation in CCR2-/- mice reveals a role for chemokines in the initiation of atherosclerosis. Nature 1998;394:894-897.

35. Bousquenaud $M$, Schwartz $C$, Léonard $F$ et al. Monocyte chemotactic protein 3 is a homing factor for circulating angiogenic cells. Cardiovasc Res 2012;94:519-525.

36. Boring L, Gosling J, Chensue SW et al. Impaired monocyte migration and reduced type 1 (Th1) cytokine responses in C-C chemokine receptor 2 knockout mice. J Clin Invest 1997;100:2552-2261.

37. Jia T, Serbina NV, Brandl K et al. Additive roles for MCP-1 and MCP-3 in CCR2-mediated recruitment of inflammatory monocytes during listeria monocytogenes infection. J Immunol 2008;180:6846-6853.

38. Shahrara S, Amin MA, Woods JM et al. Chemokine receptor expression and in vivo signaling pathways in the joints of rats with adjuvantinduced arthritis. Arthritis Rheum 2003:48:3568-3583.

39. Peppel K, Zhang L, Orman ES et al. Activation of vascular smooth muscle cells by TNF and PDGF: overlapping and complementary signal transduction mechanisms. Cardiovasc Res 2005;65:674-682. 